\title{
Investigation of Children and Adolescents' Mood and Self-Concept after Acquired Brain Injury
}

Kathryn Hendry, BSC(Hons) ${ }^{1}$; Tamara Ownsworth ${ }^{1}$, PHD, BA(Hons); Allison M. Waters ${ }^{1}$, $\mathrm{PhD}$; Megan Jackson, MPsych(Neuro), Bsc(Hons) ${ }^{2,3,4}$ Owen Lloyd, MPsych(Clin Neuro), Bsc(Hons) $)^{1,3,4}$

Short Title: Mood and self-concept after pediatric brain injury

\section{Affiliations:}

${ }^{1}$ School of Applied Psychology \& Menzies Health Institute of Queensland, Griffith University, Brisbane, Australia,

${ }^{2}$ University of Melbourne

${ }^{3}$ Queensland Paediatric Rehabilitation Service, The Queensland Children's Hospital, Children's Health Queensland, Brisbane, Australia

${ }^{4}$ School of Psychology, University of Queensland, Brisbane, Australia

Word count: 6263

Address correspondence to:

Professor Tamara Ownsworth

School of Applied Psychology

Griffith University, Messines Ridge Road, Mt Gravatt

4122, Australia

t.ownsworth@griffith.edu.au

+61737353307

\section{Acknowledgments:}

The authors thank all staff from the Queensland Pediatric Rehabilitation Service (QPRS) at the Queensland Children's Hospital for supporting the study and the families who so generously participated in this study. 


\begin{abstract}
Few studies have examined the self-reported mental health of children with an acquired brain injury (ABI). The current study aimed to: 1) identify levels of child-reported depressive and anxiety symptoms and poor self-concept, 2) investigate demographic and injury-related factors associated with children's mood and self-concept, and 3) examine associations between children's self-reported mental health and parents' reports of children's emotional and behavioral functioning in children specifically with traumatic brain injury (TBI). 122 children (66\% male) aged 8-16 years with ABI of mixed etiology were consecutively recruited through an outpatient rehabilitation clinic. Children were administered the Beck Youth Inventories - Second Edition, and parents completed the Adaptive Behaviour Assessment System and the Child Behaviour Checklist (CBCL). Relative to the norms, $16.4 \%$ of children scored in the clinical range for the depression and anxiety scales, and $24.6 \%$ reported clinically low self-concept. Children with lower functional status had greater anxiety symptoms. Older children (13-16 years) reported significantly higher depressive and anxiety symptoms and lower self-concept than younger children (8-12 years). A significant interaction between age and sex indicated that older girls reported greater depressive and anxiety symptoms than younger girls whereas no age-based differences were found for boys. Parent-reported total emotional and behavioral problems were positively associated with children's self-reported depressive and anxiety symptoms and were negatively correlated with self-concept. These findings indicate that adolescents, particularly girls, may be at heightened risk of poor mental health following ABI. Further research investigating the reasons for these demographic differences may inform developmentally sensitive interventions.
\end{abstract}

Key Words: Acquired Brain Injury, Mental Health, Mood, Self-Concept, Child, Adolescent. 


\section{Introduction}

Acquired brain injury (ABI) is a broad term encompassing several different injury etiologies. ABI may arise from external mechanisms (i.e., traumatic brain injury [TBI]) or internal mechanisms such as stroke, infection or brain tumor (Australian Institute of Health and Welfare, 2007). As the most common cause of ABI worldwide, TBI has an estimated prevalence of 691 per 100,000 children, with those resulting in hospitalization estimated as 74 per 100,000 (Thurman, 2016). Children with ABI from both internal and external causes typically experience diverse functional effects extending across physical, cognitive and language, behavioral, and emotional domains (Forsyth \& Kirkham, 2012).

Impairments in emotional and behavioral functioning in particular have been found to have adverse effects on children's psychosocial functioning (Anderson et al., 2013; Catroppa et al., 2015; Catroppa et al., 2017; Rosema, Crowe, \& Anderson, 2012; Zyrianova, Alexander, \& Faruqui, 2016). Parents commonly report emotion regulation difficulties for their children, such as irritability, agitation, reduced capacity to manage stress and frustration, and externalizing and internalizing problems (i.e., depression, anxiety, and withdrawal) (Catroppa et al., 2017; Max et al., 2012; Pastore et al., 2013; Pastore et al., 2014; Poggi et al., 2009). Such difficulties may arise from direct damage to fronto-limbic structures that underlie emotion processing and regulation and/or relate to a psychological reaction to their changing life circumstances (Jorge et al., 2004; Ownsworth et al., 2011). Children with ABI face the challenge of adjusting to their post-injury impairments and associated changes in lifestyle, family and peer relationships, and school and vocational pursuits (Wakefield et al., 2010; Bilbao et al., 2003; Pastore et al., 2014). In turn, children's psychological well-being, including their emerging self-concept or global beliefs 
about their own competency and self-worth, can be negatively affected by ABI (Ownsworth, 2014).

To date, pediatric research has largely focused on the effects of ABI on neurocognitive function, adaptive functioning, and academic and social functioning, with studies typically highlighting enduring adverse effects (Babikian, \& Asarnow, 2009; Catroppa, et al., 2017; de Kloet et al., 2015; Prasad, Swank, Ewing-Cobbs, 2017; Yeates et al., 2002). Fewer studies have investigated the impact of ABI on children's mental health and self-concept, and most existing studies have assessed these psychological outcomes using parent-report measures rather than self-report (Gomes, Rinehart, Greenham, \& Anderson et al., 2014; Pastore et al., 2013; Yeates, Taylor, Walz, Stancin, \& Wade, 2010). Studies employing clinician-rated interviews and/or parent reports have indicated that approximately 38-63\% of children develop mental health conditions following TBI, which is considerably higher than rates (13-14\%) following orthopedic injuries (Luis \& Mittenberg, 2002; Max et al., 2012). Similarly, in a study on children with ABI of mixed etiology, nearly half (47.2\%) demonstrated clinical levels of behavioral and emotional problems, as rated by parents (Pastore et al., 2014).

In a study using both child self-report and parent report measures (Kirkwood et al. 2000), children aged 6-12 years with moderate and severe TBI were at significantly greater risk of experiencing persisting depressive symptoms at 6 and 12 months post-injury than children with orthopedic injuries. Although levels of self-reported depression did not differ between the groups soon after injury, level of depressive symptoms remained relatively stable across time for the TBI group, but declined significantly between baseline and at 6 and 12 months post-injury for the orthopedic group (Kirkwood et al., 2000). Based on parent reports, children with severe TBI were six times more likely than children with orthopedic injuries to display clinically elevated 
depressive symptoms at 6 months and were 2.6 times more likely to at 12 months. Child and parent reports of depression were significantly correlated in the TBI sample $(r=.29-.39)$ but not in the orthopedic sample.

There has been a growing emphasis in wider pediatric and mental health research on the inclusion of children's perspectives on their own well-being, recognizing children as competent interpreters capable of communicating how they see and experience themselves (Mason \& Danby, 2011; McDougall, Bedell, \& Wright, 2013). However, in pediatric ABI research parent reports are often more relied upon to assess children's functioning, possibly due to concerns that children's self-awareness or capacity to accurately appraise and self-report their own functioning may be compromised (Butler \& Gasson, 2005; Lloyd, Ownsworth, Fleming, \& ZimmerGembeck, 2015). Although such issues provide a good rationale for the inclusion of parent or significant others' reports regarding children's functional status, seeking multiple perspectives including that of the child, is likely to provide a fuller picture of the mental health of children and adolescents with ABI (Dockett, Einarsdottir, \& Perry, 2009; Lloyd et al., 2015; McDougall et al., 2013). The pediatric ABI research that has included child and parent-proxy reports of psychosocial functioning has generally found low to moderate associations between the two (Bell, Ownsworth, Lloyd, Sheeran, \& Chambers, 2018), which is consistent with the general pediatric literature (De Los Reyes et al., 2015). Notably, parents typically report greater behavioral or externalizing problems than children with ABI, yet often rate their child's selfesteem higher than child self-reports (Bell et al., 2018).. Due to the inherently subjective nature of self-perceptions and mood symptoms it is possible that parents underestimate children's distress and the negative effects on their self-concept. 
To date, relatively few studies have examined the impact of pediatric ABI on self-concept from the child's perspective. Existing studies indicate that children and adolescents with ABI report significantly lower self-esteem than age and sex-matched controls (Andrews, Rose, \& Johnson, 1998; Hawley, 2012; Pastore et al., 2015). Andrews et al. (1998) found that children aged 6-18 years with TBI $(n=54)$ reported significantly lower levels of self-esteem than age and sex-matched controls, along with higher levels of loneliness and behavioral problems. Similarly, Hawley (2012) examined self-esteem in 96 children (5-15 years) with TBI and found that they reported significantly lower self-esteem than their typically developing peers. In one of the few studies to include children with brain injuries arising from differing etiologies, Pastore et al. (2015) found that adolescents (12-18 years) with TBI and stroke reported significantly lower self-esteem than age and sex-matched controls. Interestingly, only female adolescents with ABI rated their sexual attractiveness as lower than controls, whereas both females and males with $\mathrm{ABI}$ rated their physical appearance as significantly poorer than typically developing peers. Adolescents with TBI and stroke did not significantly differ in their self-perceptions (Pastore et al., 2015).

Diverse factors potentially influence children's self-perceptions, mood and broader psychological adjustment following ABI. A leading neuro-developmental theory on recovery and adjustment to brain injury contends that children injured at a younger age are more vulnerable to poor functional outcomes (Anderson, 2001; Anderson, Northam, Hendy, \& Wrennall, 2017). More generally, research supports a "double hazard" model concerning the heightened vulnerability to poorer neurocognitive outcomes of children who sustain both an early and severe brain injury, due to the disrupted development of the maturing brain (Anderson, Catroppa, Morse, Haritou, \& Rosenfeld, 2005). In their meta-analysis, Babikian and Asarnow (2009) 
reported evidence of a widening gap from typical neurocognitive development over time for children sustaining a severe TBI at an early age. However, the picture is less clear when it comes to behavioral and psychological functioning. In their review of pediatric TBI literature Li and Liu (2013) found mixed findings regarding the impact of age at onset and injury severity on children's behavioral and psychological outcomes. Based upon the double hazard model, it is possible that age of onset and severity of injury/disability have additive effects on children's mental health outcomes, however these have yet to be investigated. In ABI resulting from multiple causes, functional status measures provide a better indication of severity of disability than Glasgow Coma Scale and duration of post-traumatic amnesia, as the latter indices are not typically obtained for children with causes of ABI other than TBI (e.g., stroke, infection, tumor, or hypoxia).

There is some preliminary evidence suggesting that psychological outcomes may differ according to etiology of ABI (Pastore et al., 2014; Pastore et al., 2018), although very few studies have specifically compared the outcomes of children with different causes of ABI (Pastore et al., 2013; Poggi et al., 2005). Most studies have focused on specific etiology groups to avoid the potentially confounding issue of different mechanisms of injury and pre-injury risk factors. Yet, etiology of ABI is an important consideration given that children with different causes of ABI are typically managed through the same pediatric rehabilitation services. Hence, identifying subgroups at greater risk of poor psychological outcomes is a priority for clinical management.

In summary, pediatric $\mathrm{ABI}$ has been found to have negative effects on mental health including children's emerging self-concept. However, there are significant gaps in understanding of children's own perspectives of their mental health after ABI. 


\section{Aims and Hypotheses}

The primary objective of this study was to investigate the impact of ABI on children and adolescents' mental health, namely their self-reported mood (depressive and anxiety symptoms) and self-concept. The specific aims were to: 1) characterize the mood and self-concept of children and adolescents (aged 8-16 years) with ABI relative to the norms; and 2) investigate demographic and injury factors (e.g., etiology, age at onset, and functional status) related to children's mood and self-concept. The secondary objective was to examine associations between children's self-reported mood and self-concept, and parents' reports of children's emotional and behavioral functioning.

Due to the exploratory nature of this study, no specific hypotheses were made regarding the influence of etiology on mood and self-concept. However, in line with the double hazard model, it was hypothesized that children who sustained an ABI earlier in life and those with poorer functional status would report significantly greater depressive and anxiety symptoms and more negative self-concept than those who sustained ABI later in childhood, or those with better functional status. In relation to the second objective, we hypothesized that children's selfreported mood and self-concept would be significantly related to parent ratings of children's emotional and behavioural functioning. It was also hypothesized that rates of parent-reported externalizing problems would be higher than parent-reported internalizing problems.

\section{Methods}

\section{Participants}

Children and adolescents with ABI were consecutively recruited through an outpatient rehabilitation clinic at a major metropolitan hospital in Brisbane, Australia, between January 
2016 and February 2017. Children with TBI were recruited as part of a broader study that examined factors related to self-awareness (Lloyd, Ownsworth, Fleming, Jackson \& ZimmerGembeck, 2019). Treating clinicians screened prospective participants based on the following inclusion criteria: history of ABI (i.e., brain injury sustained through internal or external mechanisms with onset $>40$ days after birth); currently aged 8-16 years; absence of a major psychiatric disorder (e.g., psychosis) or neurodevelopmental disorder prior to injury; absence of significant sensory/perceptual deficits that would limit the individual's ability to complete selfreport measures; and adequate understanding of spoken and written English. Children with a history of abuse or neglect (i.e., involvement in child protective services), or those presenting with extreme distress that warranted urgent psychiatric referral were excluded.

\section{Sample Characteristics}

As shown in Figure 1, of the 306 children receiving rehabilitation from the outpatient clinic during the recruitment period, a total of 224 children met the eligibility criteria, of which 46 did not participate; 26 declined and 20 were missed in recruitment due to not attending their scheduled appointment. Data were not available for a further 56 children who consented to participate but subsequently withdrew $(n=18)$ or did not complete the key measure (BYI-II) relevant to this study $(n=38)$. Consequently, the final sample included 122 children.

Independent $t$-tests and chi-square tests showed that there were no significant differences between the final sample $(n=122)$ and children who were eligible but did not participate $(n=$ 102 ) in terms of participant's age at injury, $t(206)=-.20, p=.84$; age at assessment, $t(212)=$ $1.83, p=.98$; time since onset $, t(206)=.69, p=.49$, or etiology in terms of TBI versus other $\operatorname{ABI}\left(\chi^{2}(1,215)=1.20, p=.27\right)$. 
As shown in Table 1, the ABI sample included 41 female and 81 male children, who sustained their injury from five causes, including TBI (52\%), stroke (17\%), brain tumor (15\%), infection (13\%) and hypoxia (3\%). Hence, 63 children sustained a TBI and 59 had other causes (other ABI). Children's age at assessment ranged from 8 to 16 years and age at injury ranged from one month to 16.5 years.

Insert Table 1 about here

\section{Measures}

Mental health and self-concept: Beck Youth Inventories - Second Edition (BYI-II).

The BYI-II (Jolly, \& Steer, 2005) is a widely used self-report measure of mood and self-concept in children aged 7-18 years. The BYI-II is comprised of five self-report inventories: depression, anxiety, anger, disruptive behavior, and self-concept. Only the depression, anxiety and selfconcept inventories were administered in this study. Each inventory consists of 20 statements (e.g. "I have trouble sleeping") which children rate according to the frequency with which the statement applied to them ("never" =0, "sometimes" =1, "often" =2, "always" = 3). Raw scores are calculated by summing all item responses for each scale (range: $0-60$ ) and then converted to $T$-scores, based on sex and age norms. For the Depression (BDI) and Anxiety (BAI) inventories, $T$-scores of $<55$ indicate 'average' symptomatology, 55-59 = 'mildly elevated', 60-69= 'moderately elevated' and 70+ = 'extremely elevated'. $T$-scores of $\geq 60$ were considered clinically significant. For the Self-concept inventory (BSCI), $T$-scores $<40$ indicate ' $m u c h$ lower than average' self-concept, 40 to $44=$ 'lower than average', 45 to $55=$ 'average', and $>55=$ 'above average'. $T$-scores of $<45$ indicated clinically low levels of self-concept (Jolly, \& Steer, 2005). 
Strong psychometric properties have been reported for the BYI-II, including good internal consistency $(\alpha=.86-.96)$, test-retest reliability $(r=.74-.93)$ and validity, and it has been used extensively in research with both typically developing and chronic illness populations (Jolly, \& Steer, 2005; Thabrew, McDowell, Given \& Murrell, 2017). Internal consistency for the BYI-II in the current ABI sample ranged from good to excellent (BDI $\alpha=.91$; $\mathrm{BAI} \alpha=.85$; BSCI $\alpha=.88)$.

\section{Functional status: Adaptive Behaviour Assessment System - Third Edition (ABAS-}

3). The ABAS-3 (Harrison \& Oakland, 2015) is a multidimensional norm-referenced (birth to 89 years of age) measure. The parent/primary caregiver form (Ages 5-21 years) was used to assess children's functional status or daily living skills across three domains (conceptual, social and practical) that comprise 10 skill areas (communication, community use, functional academics, health and safety, home or school living skills, leisure, self-care, self-direction, social, and work). In addition to the overall age-standardised score (Global Adaptive Composite or GAC), index scores for the conceptual, social and practical domains were derived. The ABAS is a widely used measure in pediatric ABI research (Catroppa et al., 2017; McCauley et al., 2012). Sound internal consistency $(\alpha=.72-.99)$, and test-retest reliability $(r=.70-0.89)$ have been reported for this measure (Harrison \& Oakland, 2015).

Emotional and behavioural functioning: Child Behaviour Checklist (CBCL). The CBCL (Achenbach \& Rescorla, 2001) is a widely used 113 item measure of internalizing and externalizing behavior in children aged 6-18 years. As data were collected as part of a broader TBI study (Lloyd et al., 2019) which did not include the Youth Self-Report (for ages 11-18 years), only parents of children with TBI completed the CBCL. Using age and sex norms, raw scores are converted to $T$-scores for the three summary scales (Internalizing, Externalizing, and 
Total Problems) and eight syndrome subscales (Withdrawn/Depressed, Somatic Complaints, Anxiety/Depression, Social Problems, Thought Problems, Attention Problems, Rule-Breaking Behavior, Aggressive Behaviour). Two summary scales incorporate a number of these; Internalising Problems (Anxious/Depressed, Withdrawn/Depressed, Somatic Complaints) and Externalising Problems (Rule-Breaking Behavior and Aggressive Behavior). The Total Problems score is a composite of all problem behavior subscales. Standardised scores of $T \geq 60$ are considered to fall in the clinical range for summary scales. Excellent internal consistency ( $\alpha=$ .78-.97), test-retest reliability $(r=.90)$, and inter-rater reliability $(r=.93)$ have been reported for the CBCL (Achenbach \& Rescorla, 2001), which is commonly used with pediatric brain injury populations (Catroppa et al., 2015; McCauley et al., 2012).

\section{Procedure}

Ethical approval was obtained from both hospital and university human ethics committees. Treating clinicians screened children for eligibility and approached prospective participants. Both the participating parent/caregiver and child/adolescent were asked to provide informed consent. Children were administered the Self-Concept, Depression and Anxiety scales of the BYI-II in person, with a clinician available to assist as needed. Parents/caregivers completed the ABAS-3 in person or over the telephone (as preferred). Similarly, parents/caregivers of children with TBI were also administered the CBCL in person or over the telephone. Information pertaining to children's ABI was accessed from medical records.

\section{Data Analysis}

Data analysis was conducted using the Statistical Package for the Social Sciences version 24. Missing data and assumptions for parametric analyses were examined and managed according to procedures outlined by Tabachnick and Fidell (2013). Independent $t$-tests or one- 
way ANOVA were conducted to examine between-group differences in children's mood and self-concept according to etiology of ABI, age at onset, current age, and sex. For age at onset and current age children were grouped into age bands as guided by prior research and developmental literature, with the following bands for age at onset: $<4,4$ to 7,8 to 12,13 to 16 years (Anderson et al., 2001; Harter, 2012). For significant between-group differences, chi-square tests were used to compare the proportion of children with clinically elevated levels of depression, anxiety and low self-concept. Pearson's correlations were used to examine associations between other demographic and injury-related variables and mood and self-concept. To examine additive effects or potential interactions between demographic and injury variables related to mood and self-concept, two-way ANOVA (categorical variables) or moderated hierarchical regression analyses (continuous variables) were conducted.

\section{Results}

\section{Self-reported Mental Health and Self-Concept}

Descriptive data on children's mood, self-concept and adaptive behavior are summarized in Table 2. For the total sample, TBI and other ABI groups, the mean $T$-scores were all in the average range for the BYI-II indices. Overall, $16.4 \%$ participants scored in the clinical range $(T \geq$ 60) for depression and anxiety. A slightly higher proportion (24.6\%) reported clinically low selfconcept. Thirteen of the 20 children scoring in the clinical range for depression also scored in the clinical range for anxiety. Fourteen of the 30 children scoring in the clinical range for selfconcept also scored in the clinical range for depression, and 10 children scored in the clinical range on all three scales.

Insert Table 2 about here 


\section{Demographic and injury-related factors associated with mood and self-concept}

Due to the small number of children with hypoxia $(n=4)$, these children were omitted from the etiology specific comparisons; however, they were included in the "other ABI" subgroup for comparisons with children with TBI. No significant differences were found according to etiology subgroup (Infection, Stroke, Tumor, TBI) for children's self-reported depressive symptoms, $F(3,118)=.85, p=.47, n_{p}{ }^{2}=.02$; anxiety symptoms, $F(3,118)=1.12, p$ $=.35, n_{p}{ }^{2}=.03$; or self-concept, $F(3,118)=1.73, p=.17, n_{p}{ }^{2}=.04$. There were also no significant differences between the other ABI and TBI subgroups for self-reported depressive, $F(1,121)=1.40, p=.24, n_{p}{ }^{2}=.01$; anxiety symptoms, $F(1,121)=2.19, p=.14, n_{p}{ }^{2}=.02$; or self-concept, $F(1,121)=1.44, p=.23, n_{p}{ }^{2}=.01$.

Further, no significant differences were found according to age at onset for depressive symptoms, $F(3,121)=1.59, p=.20, n_{p}{ }^{2}=.04 ;$ anxiety symptoms, $F(3,121)=1.59, p=.20, n_{p}{ }^{2}$ $=.04$; or self-concept, $F(3,121)=.38, p=.77, n_{p}{ }^{2}=.01$. However, there was a significant difference according to participants' current age, with older children (13-16 years) reporting significantly higher depressive symptoms $(M=52.04, S D=10.84)$ than younger children $(8-12$ years; $M=45.47, S D=8.60), F(1,121)=13.89, p<.001, n_{p}{ }^{2}=.10$. Similarly, older children reported significantly higher anxiety symptoms $(M=52.45, S D=10.30)$ than younger children $(M=47.78, S D=9.87), F(1,121)=6.11, p=.02, n_{p}{ }^{2}=.05$, as well as significantly poorer selfconcept $(M=48.90, S D=9.07)$ than their younger counterparts $(M=53.03, S D=8.79)$, $F(1,121)=4.78, p=.03, n_{p}^{2}=.04$. Furthermore, a significantly higher proportion of older children (26.8\%) scored in the clinical range for depression compared to younger children (7.6 $\%), \chi^{2}(1, n=122)=8.16, p<.01$. The age groups did not significantly differ in the proportion of participants scoring in the clinical range for anxiety or self-concept $(p>.05)$. No significant 
differences were found according to children's sex for self-reported mood or self-concept ( $p$ $>.05)$.

Table 3 displays the correlations between demographic and injury-related factors and the depression, anxiety, and self-concept indices of the BYI-II. Children with better functional status on the ABAS GAC, conceptual and practical domains reported fewer anxiety symptoms ( $r=$ $.22, p<.05)$. Further, there was a significant association between functional status on the ABAS social domain and self-concept $(r=.20, p<.05)$, indicating that children with better social functioning had more positive self-concept. There were no other significant associations between the demographic and injury-related factors and mental health outcomes. Children's self-concept was significantly and negatively associated with depressive $(r=-.58, p<.001)$ and anxiety $(r=$ $.43, p<.001)$ symptoms. Further, anxiety and depressive symptoms were significantly and positively associated $(r=.73, p<.001)$.

Insert Table 3 about here

\section{Interactions between demographic and injury-related variables for mood and self-concept}

As shown in Table 4, the regression analyses indicated that functional status (ABAS GAC) and age at onset were not significantly related to depressive symptoms or self-concept ( $p$ $>.05$ ). However, poorer functional status was significantly related to greater anxiety symptoms $(p<.01)$ independent of age at onset. There were no significant interactions between functional status and age at onset $(p>.05)$.

Insert Table 5 about here

Due to the significant univariate associations between functional status and current age and children's mood and self-concept, further analyses were conducted to determine whether these relationships were moderated by other demographic and injury-related factors. There were 
no significant interactions between functional status and current age and the variables of sex, education, time since injury, and cause of ABI (TBI vs. other ABI) for mood or self-concept $(p>.05)$

However, there was a significant interaction between current age (8-12 vs. 13-16 years) and sex for depressive symptoms $\left(F(3,121)=4.34, p<.05, n_{p}{ }^{2}=.04\right)$ and anxiety symptoms $\left(F(3,121)=5.08, p<.05, n_{p}{ }^{2}=.04\right)$, but not for self-concept $\left(F(3,121)=.26, p=.61, n_{p}{ }^{2}=.00\right)$. As shown in Figure 2, pairwise comparisons identified that younger females reported significantly lower depressive (BDI: $t[39]=-3.44, p=.001, d=1.11$ ) and anxiety symptoms (BAI: $t[39]=-3.66, p=.001, d=1.19)$ than older females. However, there were no significant differences in depressive and anxiety symptoms between younger and older males (BDI: $t$ [79] $=$ $-1.75, p>.05, d=0.40$; BAI: $t[79]=-0.82, p>.05, d=0.18)$.

Insert Figure 2 about here

\section{Associations between children's self-reported mood and self-concept and parent ratings of children's emotional and behavioral functioning (TBI only)}

Data were missing for eight parents on the CBCL. Descriptive data on the CBCL for 55 children with TBI are reported in Table 5 . Overall, $54.5 \%$ of children with TBI were in the clinically significant range on the CBCL total problems scale $(M=58.89, S D=11.15)$ and the internalizing scale $(M=58.89, S D=12.98)$. A lower percentage $(32.7 \%)$ were in the clinically significant range for externalizing problems $(M=55.73, S D=9.90)$. Sixteen of the 30 children scoring in the clinical range for internalizing problems also scored in the clinical range for externalizing problems. All but one of the children who scored in the clinical range for externalizing problems also scored in the clinical range for internalizing problems. 
As reported in Table 5, significant correlations were found between the BYI-II scales and many of the parent-reported scales on the CBCL $(p<.05)$. Focusing on summary scales, moderate sized correlations were generally found between parent-reported CBCL total problems and internalizing problems and children's self-reported depressive and anxiety symptoms, and self-concept. Parent-reported externalizing problems on the CBCL were only significantly correlated with children's self-concept, with higher levels of externalizing behavior associated with less positive views of self.

Insert Table 5 about here

Further analysis was conducted to identify demographic and injury variables associated with parent reports of children's emotional and behavioral functioning. Greater total problems on the CBCL were significantly associated with sustaining an injury at an earlier age $(r=-.29$, $p<.05)$, greater time since injury $(r=.36, p<.05)$ and more severe TBI $(r=.33, p<.05)$. Externalizing problems were positively associated with time since injury $(r=.33, p<.05)$, and severity of injury $(r=.34, p<.05)$. Internalizing problems were not significantly correlated with any demographic or injury variables $(p>.05)$. However, there was a significant interaction between current age (8-12 vs. 13-16 years) and sex for the internalizing scale of the CBCL, $F(3$, $54)=4.25, p<.05, n_{p}{ }^{2}=.08$. There was a tendency for older females to have greater internalizing problems $(M=62.54, S D=11.0)$ than younger females $(M=54.1, S D=18.1)$, whereas younger males had greater internalizing problems $(M=61.88, S D=10.3)$ than older males $(M=55.35, S D=13)$. However, none of these pairwise comparisons were significant (Females: $t[19]=-1.31, p>.05$; Males: $t[32]=1.61, p>.05$ ).

In summary, there was a significant age $\mathrm{x}$ sex interaction for self-reported depressive and anxiety symptoms for the broader ABI sample. Similarly, when examining parent-reported 
emotional and behavioral functioning for the TBI subgroup, a significant interaction between current age and sex was found on the internalizing scale of the CBCL, although the pairwise comparisons were not significant.

\section{Discussion}

The present study aimed to investigate the impact of ABI on the self-reported mood and self-concept of children and adolescents, and to investigate demographic and injury-related factors related to these mental health outcomes. Overall, $16.4 \%$ of children scored in the clinical range for depressive and anxiety symptoms, while $24.6 \%$ of children reported clinically low selfconcept. Thus, the majority of children and adolescents were not experiencing clinically elevated mood symptoms or poor self-concept. There were no significant differences in mood or selfconcept according to etiology of injury. In relation to the first hypothesis, poorer functional status was significantly related to higher anxiety symptoms; however, age at injury was not significantly related to mood symptoms or and self-concept. A key finding was that adolescent girls reported greater symptoms of depression and anxiety than younger girls, whereas no age difference was found for boys. In support of the second hypothesis, significant associations were typically found between children's self-reported mood and self-concept and parents' reports of emotional and behavioral functioning (CBCL total and internalizing scales). Contrary to the third hypothesis, rates of parent-reported internalizing problems were higher than their reports of externalizing problems.

Approximately one in four (self-concept) and nearly one in five (depression/anxiety) children reported clinically significant levels of poor self-concept and/or mood symptoms, respectively. Such rates are higher than rates of anxiety and depression reported for children and 
adolescents in the general community based on both Australian (6.9-7.7\%; Lawrence et al., 2016) and US (3.2-7.1\%; Ghandor et al., 2018) data. Yet, these rates are lower than those cited in other pediatric ABI research (35-49\%; Kirkwood et al., 2000; Luis \& Mittenberg, 2002; Max et al., 2012). A potential explanation for the lower rates compared to other pediatric ABI research relates to methodological differences such as the inclusion/exclusion criteria, use of the BYI-II and the sample characteristics. For instance, the current study excluded children experiencing extreme levels of distress that warranted psychiatric referral, which is likely to have resulted in an underrepresentation of the proportion of children experiencing distress in the clinical population. Further, the BYI-II may be less sensitive to indicators of clinical distress than a semistructured interview approach incorporating both child and parent perspectives, such as that used by Max et al. (2012).A further key difference is that the current study included children at much longer time since onset ( 1 month to 16 years post-onset), compared to previous studies, which were conducted more uniformly at early phases of recovery ( 3 or 6 months post-injury; Kirkwood et al., 2000). Thus, the lower levels of mood symptoms and poor self-concept may reflect long-term adjustment to their post-injury circumstances. Consistent with Pastore et al. (2015), there were no significant differences in mood symptoms or self-concept according to etiology of injury. As such, it may be more meaningful to focus on the variability in children's mental health outcomes within each etiology group, to determine risk factors for poor psychological adjustment (see Bell et al., 2018).

Overall, there was partial support for the hypothesis that children with lower functional status have poorer mental health outcomes, in terms of anxiety symptoms. Additionally, lower functioning on the ABAS social domain was significantly associated with more negative selfconcept. Caution is needed in inferring the direction of association between these constructs. For 
example, greater social competency may foster more positive self-perceptions. Alternatively, having a more positive self-view may facilitate greater skill development in social situations. Notably, age at injury was positively associated with functional status $(r=.51)$. It is possible that the impact of age at injury and functional status on children's mood and self-concept is moderated by their self-awareness. Indeed, Lloyd et al., (2017) found that children injured at a younger age had poorer self-awareness than those injured in later childhood. Therefore, children injured at a younger age with poor functional status may have less insight into their functional impairments, thus buffering against negative impacts on their mood or self-concept. Further research is needed to test the potential moderating role of self-awareness in the relationship between the variables of age at injury and functional status and mental health.

A key finding of the current study is that older children (13-16 years) reported significantly higher depressive and anxiety symptoms and lower self-concept than younger children (8-12 years). Importantly, this finding was qualified by a significant interaction between age and sex for depressive and anxiety symptoms; specifically, older girls reported greater depressive and anxiety symptoms than younger girls, whereas no age-based differences were found for boys. A similar trend was found for parents' reports on the CBCL for children with TBI, with a significant interaction evident between age and sex for internalizing problems of the CBCL. Other studies have similarly found higher rates of anxiety and poorer psychosocial outcomes in older children than younger ones following TBI (Di Battista, Godfrey, Soo, Catroppa \& Anderson, 2014; Friefeld, Westmacott, Macgregor \& Deveber, 2011; Gomes et al., 2014; Neuner et al., 2011). Relative to younger children, who often have an inflated sense of their capabilities and attributes, adolescents tend to have more complex and realistic selfperceptions that are informed by real-world feedback (Damon \& Hart, 1982; Harter, 2012; 
Marsh \& Ayotte, 2003). Further, previous research has found that females with TBI have a heightened vulnerability for developing mental health conditions when compared to males (Gerring et al., 2009; Grados et al., 2008; Li \& Liu, 2013). Adolescent girls are found to be more self-conscious, vulnerable to criticism and concerned with interpersonal relationships than adolescent boys (O’Dea \& Abraham, 1999; Rosenberg \& Simmons, 1975). Given the functional impairments experienced after ABI, and the potential to receive negative feedback from one's peers, it is possible that $\mathrm{ABI}$ amplifies the risk of mood symptoms for adolescent girls during a developmental period of heightened self-consciousness. Further research investigating the mechanisms underlying the interactive effects of age and sex on mood symptoms is needed to guide intervention efforts.

Parents of children with TBI reported higher levels of internalizing problems $(55 \%)$ than externalizing problems (33\%), with both rates higher than levels of distress reported by children with $\mathrm{ABI}$ on the BYI-II. Given that internalizing problems are less observable than externalizing symptoms (De Los Reyes et al., 2015), these findings may suggest that parents misinterpret and overestimate their children's distress. Alternatively, it is possible that children lack insight into their own internal states, and thus underreport emotional difficulties. Overall, children's selfreported mood and self-concept were moderately associated with parents' reports of internalizing problems. However, only children's self-concept was significantly associated with externalizing problems. Although these findings do not reflect concordance or agreement between self and proxy ratings on the same tool, such results indicate that children's mood symptoms and selfconcept are generally consistent with parents' observations of their children's internalizing symptoms. Hence, children and parents appear to have similar yet unique perspectives on the child's mental health. 
Interestingly, poorer self-concept in children was significantly related to greater parentrated externalizing problems but not internalizing problems. Greater externalizing problems were related to more severe TBI and longer time since injury, thus supporting the view that emotional and behavioral disorders may emerge over time following brain injury (Li \& Liu, 2014). Externalizing behaviors may reflect the primary impact of injury or secondary impact (i.e., psychological reactions to functional impairments and their everyday implications). It is possible that problem behaviors such as rule breaking and aggression negatively impact children's participation in social activities and the quality of social interactions, which in turn lowers their self-worth (Ownsworth, 2014). The importance of children's social participation to their emerging self-concept is supported by the significant positive correlation between social functioning on the ABAS and self-concept.

Overall, the findings of the current study highlight the need to screen for and monitor children's mood and self-concept after ABI. Adolescent females may be particularly vulnerable to depressive and anxiety symptoms and, as such, may warrant more comprehensive psychological assessment and early intervention. There is sound evidence supporting the efficacy of online psychological interventions for adolescents with ABI, such as the Teen Online Problem Solving (TOPS) program, which focuses on problem-solving, communication skills, and selfregulation (Ross, Dorris, McMillan, 2011; Wade et al., 2012). It may also be beneficial to inform parents and teachers of the increased vulnerability of adolescents (girls especially) to mood and self-concept difficulties after ABI, to aid in the early identification of difficulties and subsequent engagement with appropriate supports.

\section{Limitations}


Several limitations need to be acknowledged in the current study. First, the absence of a demographically matched neurological healthy or orthopedic injury control group limits the conclusions that can be drawn about the impact of ABI on mood and self-concept. Second, the study employed a cross-sectional design, thus limiting understanding of the adjustment trajectory of children and adolescents over time with respect to their mood and self-concept. Third, due to the broad clinical sample, there was significant diversity regarding age at injury, time since injury and etiology. There was a strong negative correlation between age at onset and time since injury $(r=-.85)$, indicating that children injured at a younger age were more long-term postinjury. Further, poorer functional status was related to younger age at injury $(r=.51)$ and longer time since injury $(r=-.51)$. More specifically, children receiving long-term follow-up in the outpatient clinic were more likely to have severe disability resulting from an injury at a younger age. The inter-relatedness of these characteristics may have confounded the analysis on the additive effects of age at injury and functional status on children's mental health outcomes. Further, children displaying extreme distress (e.g., acute suicidal ideation) that warranted psychiatric referral were excluded from the current study, which may have contributed to the relatively low rates of clinically significant distress. Overall, clinical ascertainment bias and the heterogeneity of sample characteristics may affect the generalisability of findings to other pediatric brain injury settings. Finally, as the data were collected as part of a broader study that primarily focused on children with TBI, the CBCL was only administered to parents of children with TBI, and thus direct comparison of parent and child perspectives was not possible in this study. The smaller sample size for the analyses involving the CBCL may also have affected statistical power. 
Although only a minority of children aged 8-12 years were in the clinical range for selfreported mood symptoms and poor self-concept, approximately one quarter to one third of children aged 13-16 years experienced clinically significant mood symptoms or poor selfconcept. Further research is necessary to understand the factors underlying the heightened risk of poor mental health outcomes for adolescents, and girls in particular. Longitudinal research investigating the role of self-awareness and social feedback in the development of mood symptoms and poor self-concept may guide the focus of developmentally sensitive psychological interventions. In addition to identifying risk factors for poor mental health outcomes, the protective factors underlying positive psychological adjustment need to be understood to inform resilience-focused interventions (for a review, see Dray et al., 2017) for the paediatric ABI population.

\section{Conclusion}

Overall, the current findings indicated that most children with ABI did not report clinically significant mood symptoms or poor self-concept. The key factors related to children's self-reported mental health included functional status and current age, with the later moderated by sex. Female adolescents were found to be at significantly higher risk of experiencing depressive and anxiety symptoms than younger females. For the TBI sample, there were typically moderate associations between children's self-report and parent reports of the child's emotional and behavioral functioning. In terms of clinical implications, these findings support the need for routine assessment of mood symptoms and self-concept, particularly for adolescents, and especially females, in order to provide timely psychosocial interventions. 


\section{References}

Achenbach, T. M., \& Rescorla, L. A. (2001). Manual for the ASEBA School-Age Forms \& Profiles. Burlington, VT: University of Vermont, Research Center for Children, Youth, \& Families.

Anderson, V. (2001). Developmental neuropsychology: A clinical approach. Hove [England]: Psychology Press.

Anderson, V., Beauchamp, M. H., Yeates, K. O., Crossley, L., Hearps, S. J. C., \& Catroppa, C. (2013). Social competence at 6 months following childhood traumatic brain injury. Journal of the International Neuropsychological Society, 19(5), 539-550. doi:10.1017/S1355617712001543

Anderson, V., Catroppa, C., Morse, S., Haritou, F., \& Rosenfeld, J. V. (2005). Functional plasticity or vulnerability after early brain injury? Pediatrics, 116(6), 1374-1382. doi:10.1542/peds.2004-1728

Anderson, V., Godfrey, C., Rosenfeld, J. V., \& Catroppa, C. (2012). 10 years outcome from childhood traumatic brain injury. International Journal of Developmental Neuroscience, 30(3), 217-224. doi:10.1016/j.ijdevneu.2011.09.008

Anderson, V., Northam, E., Hendy, J., \& Wrennall, J. (2001). Developmental Neuropsychology: A clinical approach East Sussex, UK Psychology Press Ltd.

Anderson, V., Northam, E., \& Wrennall, J. (2017). Developmental neuropsychology: A clinical approach. Routledge.

Andrews, T. K., Rose, F. D., \& Johnson, D. A. (1998). Social and behavioural effects of traumatic brain injury in children. Brain Injury, 12(2), 133-138. doi:10.1080/026990598122755

Babikian, T., \& Asarnow, R. (2009). Neurocognitive outcomes and recovery after pediatric TBI: Meta-analytic review of the literature. Neuropsychology, 23(3), 283-296. doi: $10.1037 / \mathrm{a} 0015268$

Bell, H., Ownsworth, T., Lloyd, O., Sheeran, N., \& Chambers, S. (2018). A systematic review of factors related to children's quality of life and mental health after brain tumor. Psychooncology, 27(10), 2317-2326. doi:10.1002/pon.4850

Bilbao, A., Kennedy, C., Chatterji, S., Ustun, B., Barquero, J., \& Barth, J. T. (2003). The ICF: Applications of the WHO model of functioning, disability and health to brain injury rehabilitation. NeuroRehabilitation, 18(3), 239-250. 
Butler, R. J., \& Gasson, S. L. (2005). Self esteem/self concept scales for children and adolescents: A review. Child and Adolescent Mental Health, 10(4), 190-201. doi:10.1111/j.1475-3588.2005.00368.

Catroppa, C., Anderson, V., Beauchamp, M., Yeates K., (2016). New Frontiers in Pediatric Traumatic Brain Injury: An Evidence Base for Clinical Practice. $\left(1^{\text {st }}\right)$. NY, USA. Routelegde, Taylor \& Francis.

Catroppa, C., Crossley, L., Hearps, S. J., Yeates, K. O., Beauchamp, M., Rogers, K., \& Anderson, V. (2015). Social and behavioral outcomes: pre-injury to six months following childhood traumatic brain injury. Journal of Neurotrauma, 32(2), 109-115. doi:10.1089/neu.2013.3276.

Catroppa, C., Hearps, S., Crossley, L., Yeates, K. O., Beauchamp, M., Fusella, J., \& Anderson, V. (2017). Social and behavioral outcomes following childhood traumatic brain injury: What predicts outcome at 12 months post-insult? Journal of Neurotrauma, 34(7), 14391447. doi:10.1089/neu.2016.4594

Damon, W., and Hart, D. (1982). The Development of Self-Understanding from Infancy Through Adolescence. Child Development, 53(4), 841-864.

Di Battista, A., Godfrey, C., Soo, C., Catroppa, C., \& Anderson, V. (2014). Depression and health related quality of life in adolescent survivors of a traumatic brain injury: a pilot study. PloS one, 9(7), e101842. doi:10.1371/journal.pone.0101842

de Kloet, A. J., Gijzen, R., Braga, L. W., Meesters, J. J., Schoones, J. W., \& Vliet Vlieland, T. P. (2015). Determinants of participation of youth with acquired brain injury: A systematic review. Brain Injury, 1-11. doi:10.3109/02699052.2015.1034178.

De Los Reyes, A., Augenstein, T. M., Wang, M., Thomas, S. A., Drabick, D. A. G., Burgers, D. E., \& Rabinowitz, J. (2015). The validity of the multi-informant approach to assessing child and adolescent mental health. Psychological Bulletin, 141(4), 858-900. doi: $10.1037 / \mathrm{a} 0038498$

Dockett, S., Einarsdottir, J., \& Perry, B. (2009). Researching with children: ethical tensions. Journal of Early Childhood Research, 7(3), 283-298. doi:10.1177/1476718x09336971.

Dray, J., Bowman, J., Campbell, E., Freund, M., Wolfenden, L., Hodder, R. K., McElwaine, K., Tremain, D., Bartlem, K., Bailey, J., Small, T., Palazzi, K., Oldmeadow, C., \& Small, T. (2017). Systematic review of universal resilience-focused interventions targeting child and adolescent mental health in the school setting. Journal of the American Academy of Child \& Adolescent Psychiatry, 56(10), 813-824. doi: 10.1016/j.jaac.2017.07.780

Forsyth, R., \& Kirkham, F. (2012). Predicting outcome after childhood brain injury. Cmaj, 184(11), 1257-1264. doi: https://doi.org/10.1503/cmaj.111045 
Friefeld, S. J., Westmacott, R., Macgregor, D., \& Deveber, G. A. (2011). Predictors of quality of life in pediatric survivors of arterial ischemic stroke and cerebral sinovenous thrombosis. Journal of Child Neurology, 26(9), 1186-1192. doi:10.1177/0883073811408609

Gerring, J. P., Grados, M. A., Slomine, B.,... Vassa, R. A. (2009). Disruptive behaviour disorders and disruptive symptoms after severe paediatric traumatic brain injury. Brain Injury, 23, 944-55. doi: 10.3109/02699050903285531

Gomes, A., Rinehart, N., Greenham, M., \& Anderson, V. (2014). A critical review of psychosocial outcomes following childhood stroke (1995-2012). Developmental Neuropsychology, 39(1), 9-24. doi:10.1080/87565641.2013.827197

Grados, M. A., Vasa, R. A., Riddle, M. A.,... Gerring, J. P. (2008). New onset obsessivecompulsive symptoms in children and adolescents with severe traumatic brain injury. Depression and Anxiety, 25, 398-407. doi: 10.1002/da.20398

Harrison, P. L., \& Oakland, T. (2015). ABAS-3: Adaptive behavior assessment system. Los Angeles, CA: Western Psychological Services.

Harter, S. (2012). The Construction of the Self: Developmental and Sociocultural Foundations. New York, NY 10012: Guilford Press.

Hawley, C. A. (2012). Self-esteem in children after traumatic brain injury: An exploratory study. NeuroRehabilitation, 30(3), 173-181. doi: 10.3233/NRE-2012-074

Jolly, J. B., \& Steer, R. A. (2005). Beck Youth Inventories-for children and adolescent's manual.

Jorge, R. E., Robinson, R. G., Moser, D., Tateno, A., Crespo-Facorro, B., \& Arndt, S. (2004). Major depression following traumatic brain injury. Archives of general psychiatry, 61(1), 42-50. doi: 10.1001/archpsyc.61.1.42

Kirkwood, M., Janusz, J., Yeates, K. O., Taylor, H. G., Wade, S. L., Stancin, T., \& Drotar, D. (2000). Prevalence and correlates of depressive symptoms following traumatic brain injuries in children. Child Neuropsychology, 6(3), 195-208. doi:10.1076/chin.6.3.195.3157

Lawrence, D., Hafekost, J., Johnson, S. E., Saw, S., Buckingham, W. J., Sawyer, M. G., Ainley, J., \& Zubrick, S. R. (2016). Key findings from the second Australian child and adolescent survey of mental health and wellbeing. Australian \& New Zealand Journal of Psychiatry, 50(9), 876-886. doi: 10.1177/0004867415617836

Li, L., \& Liu, J. (2013). The effect of pediatric traumatic brain injury on behavioral outcomes: a systematic review. Developmental Medicine and Child Neurology, 55(1), 37-45. doi:10.1111/j.1469-8749.2012.04414 
Lloyd, O., Ownsworth, T., Fleming, J., Jackson, M., \& Zimmer-Gembeck, M., (2019, May). Impaired Self-Awareness after Paediatric Traumatic Brain Injury: Liability or Protective Factor? Paper presented at the ASSBI/NZRA Inaugural Trans-Tasman Conference, Wellington, NZ.

Lloyd, O., Ownsworth, T., Fleming, J., \& Zimmer-Gembeck, M. J. (2015). Awareness deficits in children and adolescents after traumatic brain injury: A systematic review. J Head Trauma Rehabil, 30(5), 311-323. doi:10.1097/HTR.0000000000000113

Luis, C. A., \& Mittenberg, W. (2002). Mood and anxiety disorders following pediatric traumatic brain injury: a prospective study. Journal of clinical and experimental neuropsychology, 24(3), 270-279. doi: 10.1076/jcen.24.3.270.982

Marsh, H. W., \& Ayotte, V. (2003). Do multiple dimensions of self-concept become more differentiated with age? The differential distinctiveness hypothesis. Journal of Educational Psychology, 95(4), 687-706. doi:10.1037/0022-0663.95.4.687

Mason, J., \& Danby, S. (2011). Children as experts in their Lives: Child inclusive research. Child Indicators Research, 4(2), 185-189. doi:10.1007/s12187-011-9108-4

Max, J. E., Keatley, E., Wilde, E. A., Bigler, E. D., Schachar, R. J., Saunders, A. E., . . Levin, H. S. (2012). Depression in children and adolescents in the first 6 months after traumatic brain injury. International Journal of Developmental Neuroscience, 30(3), 239-245. doi:10.1016/j.ijdevneu.2011.12.005

McCauley, S. R., Wilde, E. A., Anderson, V., Bedell, G., Beers, S. R., Campbell, T. F., .. . Yeates, K. O. (2012). Recommendations for the use of common outcome measures in pediatric traumatic brain injury research. Journal of Neurotrauma, 29, 678-705. doi: $10.1089 /$ neu.2011.1838

McDougall, J., Bedell, G., \& Wright, V. (2013). The youth report version of the Child and Adolescent Scale of Participation (CASP): assessment of psychometric properties and comparison with parent report. Child Care Health and Development, 39(4), 512-522. doi:10.1111/cch. 12050

Neuner, B., von Mackensen, S., Krumpel, A., Manner, D., Friefeld, S., Nixdorf, S., Fruhwald, M., deVeber, G., \& Nowak-Gottl, U. (2011). Health-related quality of life in children and adolescents with stroke, self-reports, and parent/proxies reports: cross-sectional investigation. Annals of Neurology, 70(1), 70-78. doi:10.1002/ana.22381

O’Dea, J. A., \& Abraham, S. (1999). Onset of disordered eating attitudes an behaviour in early adolescence: interplay of pubertal status, gender. Adolescence, 34(136), 136.

Ownsworth, T. (2014). Self-identity after brain injury. Hove, East Sussex: Psychology Press. 
Ownsworth, T., Fleming, J., Haines, T., Cornwell, P., Kendall, M., Nalder, E., \& Gordon, C. (2011). Development of depressive symptoms during early community reintegration after traumatic brain injury. Journal of the International Neuropsychological Society, 17(1), 112-119. doi: 10.1017/S1355617710001311

Pastore, V., Colombo, K., Villa, F., Galbiati, S., Adduci, A., Poggi, G., Massimino, M., Recla, M., Liscio, M. \& Strazzer, S. (2013). Psychological and adjustment problems due to acquired brain lesions in pre-school-aged patients. Brain Injury, 27(6), 677-684. doi:10.3109/02699052.2013.775482

Pastore, V., Galbiati, S., Villa, F., Colombo, K., Recla, M., Adduci, A., Avantaggiato, P., Bardoni, A., \& Strazzer, S. (2014). Psychological and adjustment problems due to acquired brain lesions in pediatric patients: a comparison of vascular, infectious, and other origins. Journal of Child Neurology, 29(12), 1664-1671.

doi: $10.1177 / 0883073813513329$

Pastore, V., Colombo, K., Maestroni, D., Galbiati, S., Villa, F., Recla, M., ... Strazzer, S. (2015). Psychological problems, self-esteem and body dissatisfaction in a sample of adolescents with brain lesions: A comparison with a control group. Brain Inj, 29, 7-8, 937-945.

Pastore, V., Galbiati, S., Recla, M., Colombo, K., Beretta, E., \& Strazzer, S. (2018). Psychological and behavioural difficulties following severe TBI in adolescence: a comparison with a sample of peers with brain lesions of other origin and with a control group. Brain injury, 32(8), 1011-1020. doi: 10.1080/02699052.2018.1469041

Poggi, G., Liscio, M., Adduci, A., Galbiati, S., Massimino, M., Sommovigo, M., Zettin, M., Figini, E., \& Castelli, E. (2009). Psychological and adjustment problems due to acquired brain lesions in childhood: A comparison between post-traumatic patients and brain tumour survivors. Brain Injury, 19(10), 777-785. doi:10.1080/0269905500110132

Prasad, M. R., Swank, P. R., \& Ewing-Cobbs, L. (2017). Long-term school outcomes of children and adolescents with traumatic brain injury. Journal of Head Trauma Rehabilitation, 32(1), E24.

Rohde, P., Beevers, C. G., Stice, E., \& O'Neil, K. (2009). Major and minor depression in female adolescents: Onset, course, symptom presentation, and demographic associations. Journal of Clinical Psychology, 65(12), 1339-1349. doi: 10.1097/HTR.0000000000000218

Rosema, S., Crowe, L., \& Anderson, V. (2012). Social function in children and adolescents after traumatic brain injury: a systematic review 1989-2011. Journal of Neurotrauma, 29(7), 1277-1291. doi:10.1089/neu.2011.2144

Rosenberg, F. R., \& Simmons, R. G. (1975). Sex differences in the self-concept in adolescence. Sex roles, 1(2), 147-159. 
Ross, K. A., Dorris, L., \& McMillan, T. (2011). A systematic review of psychological interventions to alleviate cognitive and psychosocial problems in children with acquired brain injury. Developmental Medicine and Child Neurology, 53(8), 692-701. doi:10.1111/j.1469-8749.2011.03976

Tabachnick, B. G., \& Fidell, L. S. (2013). Using multivariate statistics, 6th edn Boston. Ma: Pearson.

Thurman, D. J. (2016). The epidemiology of traumatic brain injury in children and youths: a review of research since 1990. Journal of child neurology, 31(1), 20-27.

Wade, S. L., Walz, N. C., Carey, J., McMullen, K. M., Cass, J., Mark, E., \& Yeates, K. O. (2012). A randomized trial of teen online problem solving: Efficacy in improving caregiver outcomes after brain injury. Health Psychology, 31(6), 767. doi: $10.1177 / 0883073814544363$

Wakefield, C. E., McLoone, J., Goodenough, B., Lenthen, K., Cairns, D. R., \& Cohn, R. J. (2010). The psychosocial impact of completing childhood cancer treatment: a systematic review of the literature. Journal of Pediatric Psychology, 35(3), 262-274.

doi:10.1093/jpepsy/jsp056

Yeates, K. O., Taylor, H. G., Wade, S. L., Drotar, D., Stancin, T., \& Minich, N. (2002). A prospective study of short- and long-term neuropsychological outcomes after traumatic brain injury in children. Neuropsychology, 16(4), 514-523. doi:10.1037//08944105.16.4.514

Yeates, K. O., Taylor, H. G., Walz, N. C., Stancin, T., \& Wade, S. L. (2010). The family environment as a moderator of psychosocial outcomes following traumatic brain injury in young children. Neuropsychology, 24(3), 345-356. doi:10.1037/a0018387

Zyrianova, Y., Alexander, L., \& Faruqui, R. (2016). Neuropsychiatric presentations and outcomes in children and adolescents with primary brain tumours: Systematic review. Brain Injury, 30(1), 1-9. doi:10.3109/02699052.2015.1075590 


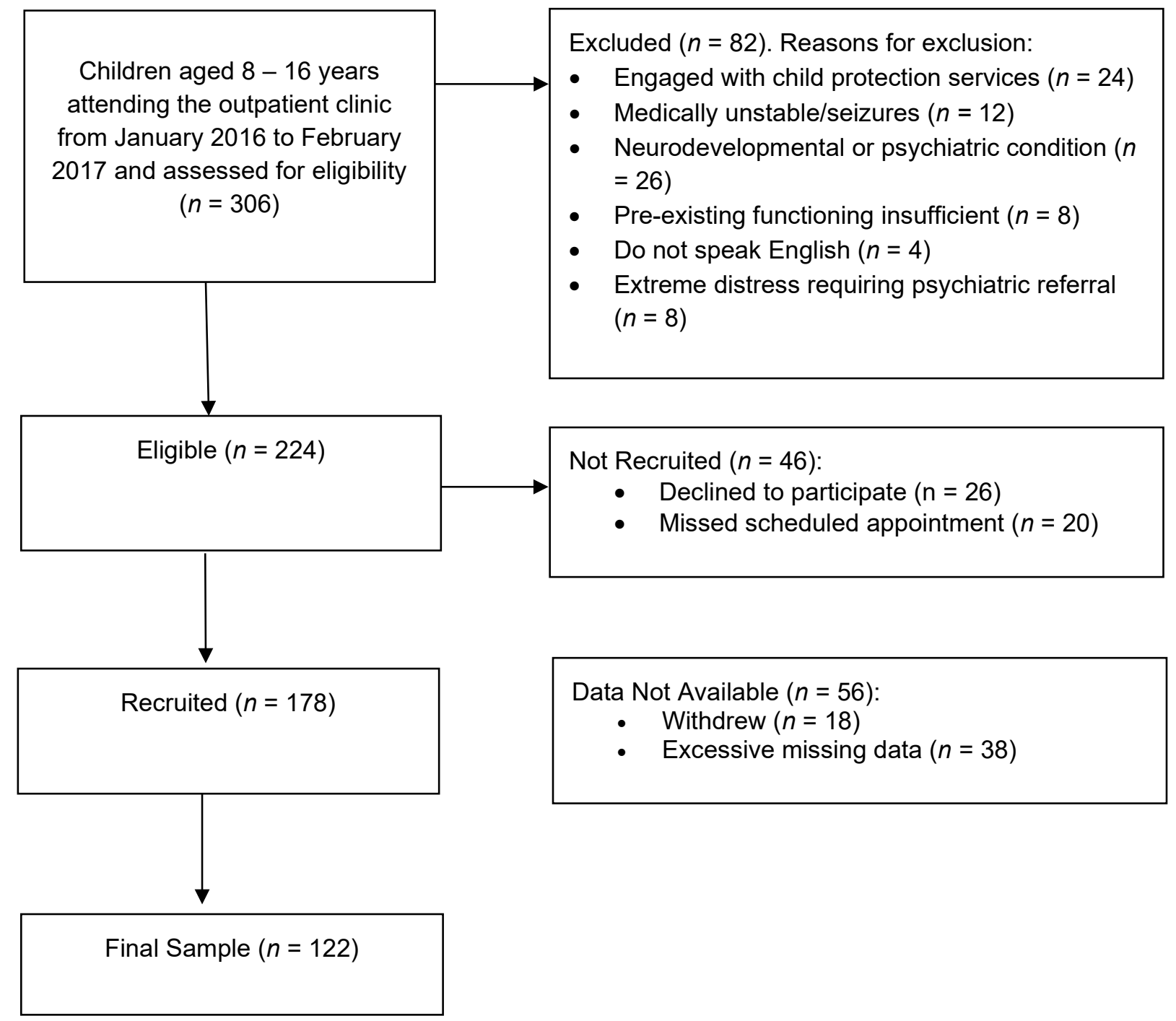

Figure 1.

Recruitment flow diagram for children with $A B I$ 


\section{Self-reported depressive symptoms}

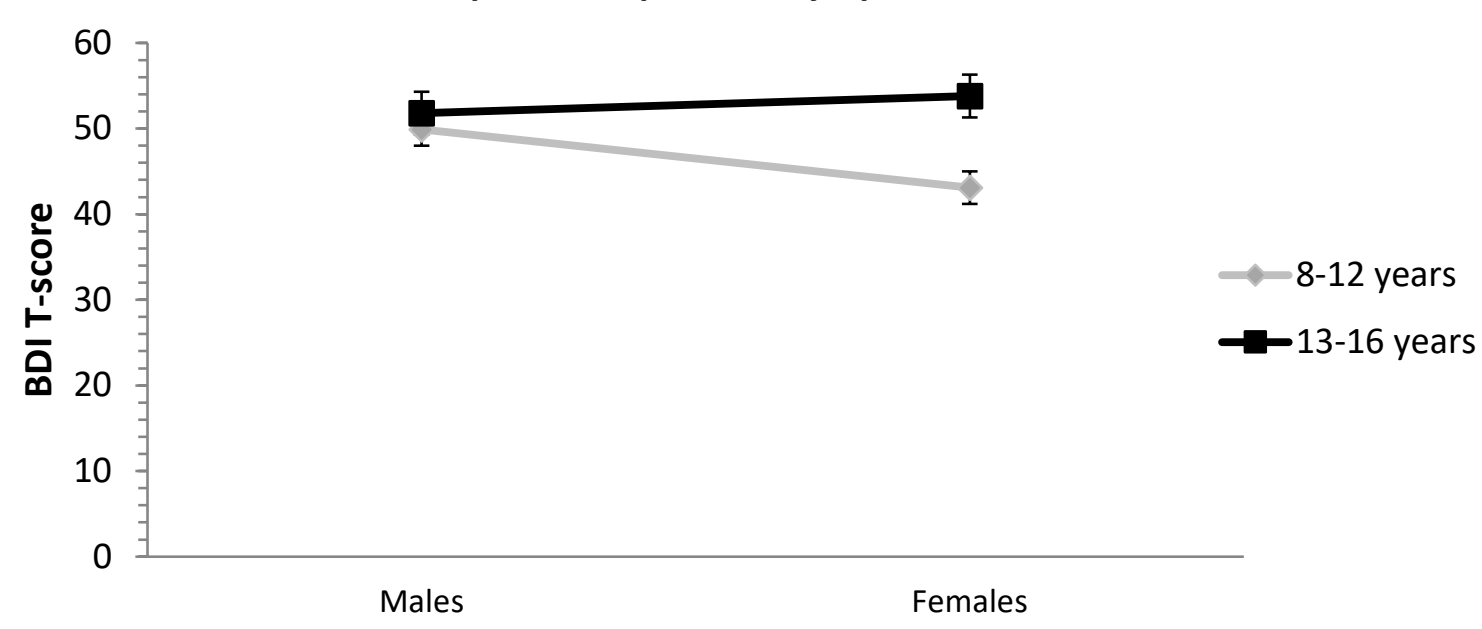

Self-reported anxiety symptoms

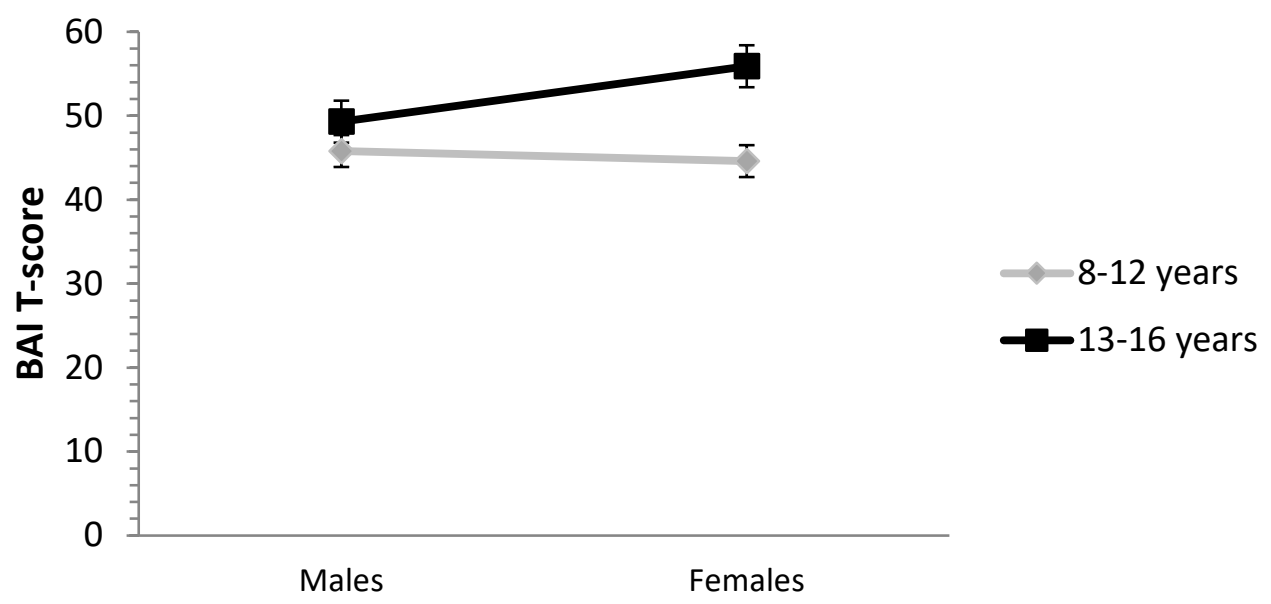

Figure 2.

Mean BDI-Y and BAI-Y scores for younger and older female and male children (note: error bars represent standard errors). 
Table 1.

Children's' Demographic and Injury Characteristics

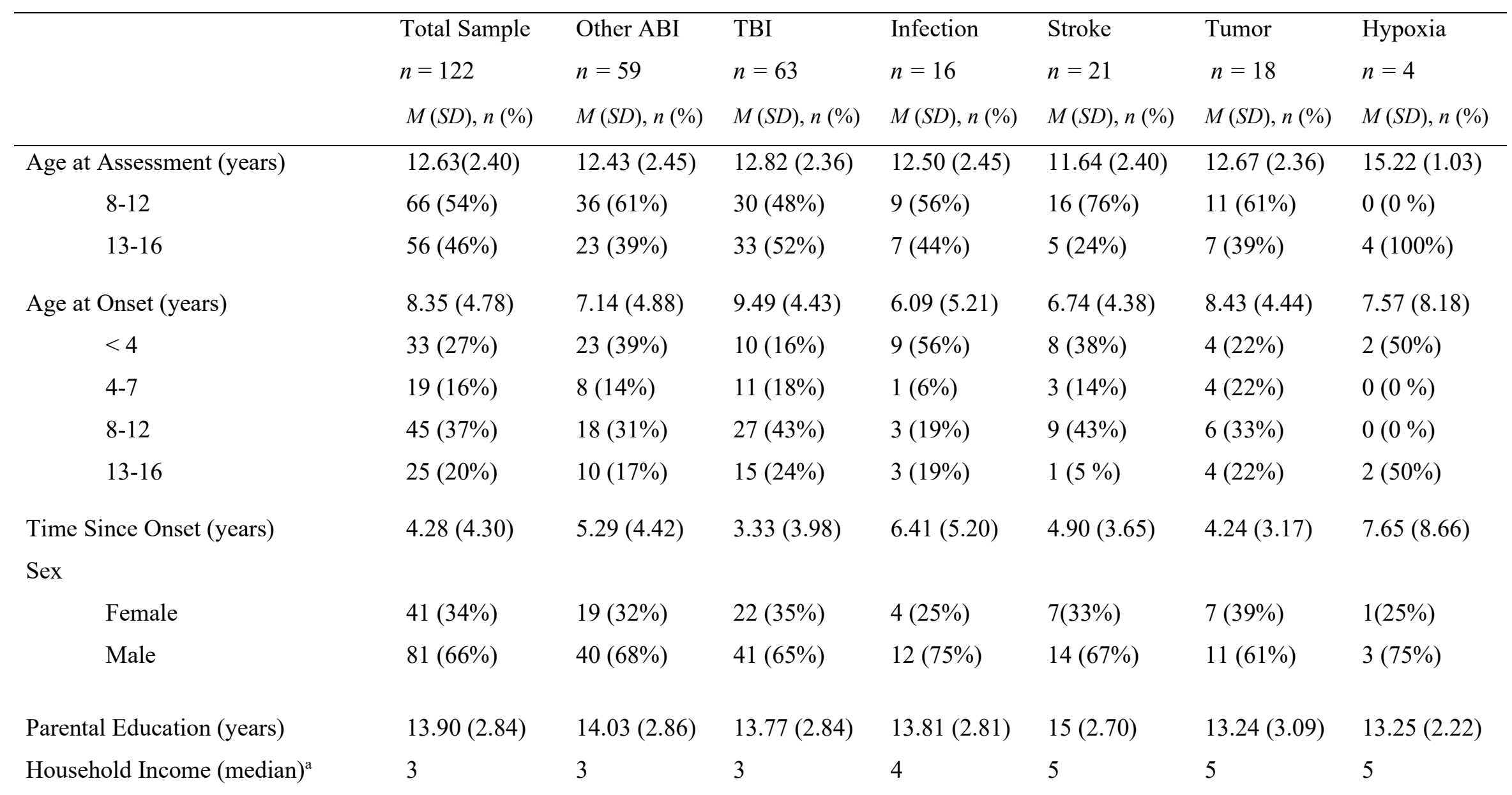

${ }^{a}$ Household income was coded as follows: $1=<\$ 40,000,2=\$ 40,000-\$ 60,000,3=\$ 60,001-\$ 80,000,4=\$ 80,001-\$ 100,000,5=\$ 100,001-\$ 120,000,6=\$ 120,001-\$ 140$, $000,7=\$ 140,001-\$ 160,000,8=\$ 160,001-\$ 180,000,9=\$ 180,001-\$ 200,00,10=>\$ 200,000$. 
Table 2

Descriptive Data on Children's Mental Health and Adaptive Behavior

\begin{tabular}{|c|c|c|c|c|c|c|c|}
\hline & $\begin{array}{l}\text { Total Sample } \\
M(S D), n(\%) \\
\text { range }\end{array}$ & $\begin{array}{l}\text { Other ABI } \\
M(S D), n(\%) \\
\text { Range }\end{array}$ & $\begin{array}{l}\text { TBI } \\
M(S D), n(\%) \\
\text { Range }\end{array}$ & $\begin{array}{l}\text { Infection } \\
M(S D), n(\%) \\
\text { Range }\end{array}$ & $\begin{array}{l}\text { Stroke } \\
M(S D), n(\%) \\
\text { range }\end{array}$ & $\begin{array}{l}\text { Tumor } \\
M(S D), n(\%) \\
\text { Range }\end{array}$ & $\begin{array}{l}\text { Hypoxia }^{\text {a }} \\
M(S D), n(\%) \\
\text { range }\end{array}$ \\
\hline \multicolumn{8}{|l|}{ BYI (T-scores) } \\
\hline Depression & $\begin{array}{l}48.48(10.20) \\
34-80\end{array}$ & $\begin{array}{l}47.36(10.27) \\
35-80\end{array}$ & $\begin{array}{l}49.54(10.10) \\
34-73\end{array}$ & $\begin{array}{l}49.50(9.06) \\
37-68\end{array}$ & $\begin{array}{l}46.86(10.77) \\
35-71\end{array}$ & $\begin{array}{l}45.83(11.20) \\
35-80\end{array}$ & $\begin{array}{l}48.25(10.21) \\
63-60\end{array}$ \\
\hline $\begin{array}{l}\text { Number }(\%) \text { in } \\
\text { clinical range }\end{array}$ & $20(16.4)$ & $9(15.3)$ & $11(17.5)$ & $2(12.5)$ & $3(14.3)$ & $3(16.7)$ & $1(25)$ \\
\hline Anxiety & $\begin{array}{l}50.15(10.41) \\
31-88\end{array}$ & $\begin{array}{l}48.71(10.59) \\
31-88\end{array}$ & $\begin{array}{l}51.49(10.15) \\
32-77\end{array}$ & $\begin{array}{l}50.25(11.11) \\
40-88\end{array}$ & $\begin{array}{l}47.76(9.11) \\
34-70\end{array}$ & $\begin{array}{l}47.44(12.05) \\
31-71\end{array}$ & $\begin{array}{l}53.25(10.94) \\
44-68\end{array}$ \\
\hline $\begin{array}{l}\text { Number }(\%) \text { in } \\
\text { clinical range }\end{array}$ & $20(16.4)$ & $8(13.6)$ & 12 (19) & $1(6.3)$ & $2(9.5)$ & $4(22.2)$ & $1(25)$ \\
\hline Self-Concept & $\begin{array}{l}50.91(9.11) \\
30-70\end{array}$ & $\begin{array}{l}51.93(8.86) \\
30-70\end{array}$ & $\begin{array}{l}49.95(9.30) \\
34-70\end{array}$ & $\begin{array}{l}47.69(5.52) \\
42-57\end{array}$ & $\begin{array}{l}53.71(10.23) \\
32-70\end{array}$ & $\begin{array}{l}52.28(8.53) \\
30-65\end{array}$ & $\begin{array}{l}58(9.42) \\
47-70\end{array}$ \\
\hline $\begin{array}{l}\text { Number }(\%) \text { in } \\
\text { clinical range }\end{array}$ & $30(24.6)$ & $11(18.6)$ & $19(30.2)$ & $5(31.3)$ & 4 (19) & $2(11)$ & $4(100)$ \\
\hline \multicolumn{8}{|l|}{ ABAS } \\
\hline GAC & $\begin{array}{l}91.02(17.02) \\
49-120\end{array}$ & $\begin{array}{l}88.58(15.83) \\
49-120\end{array}$ & $\begin{array}{l}93.64(17.98) \\
50-120\end{array}$ & $\begin{array}{l}86.13(15.06) \\
65-120\end{array}$ & $\begin{array}{l}92.38(14.61) \\
70-120\end{array}$ & $\begin{array}{l}88.39(17.24) \\
49-120\end{array}$ & $\begin{array}{l}79.25(18.88) \\
61-97\end{array}$ \\
\hline Conceptual & $\begin{array}{l}89.93(17.17) \\
49-120\end{array}$ & $\begin{array}{l}88.12(15.11) \\
49-120\end{array}$ & $\begin{array}{l}91.87(19.08) \\
51-120\end{array}$ & $\begin{array}{l}84.25(13.51) \\
63-116\end{array}$ & $\begin{array}{l}93.57(13.34) \\
74-120\end{array}$ & $\begin{array}{l}87.39(17.23) \\
49-120\end{array}$ & $\begin{array}{l}78.25(14.64) \\
63-94\end{array}$ \\
\hline Social & $\begin{array}{l}92.86(17.14) \\
34-120\end{array}$ & $\begin{array}{l}92.44(14.25) \\
59-120\end{array}$ & $\begin{array}{l}93.30(19.86) \\
34-120\end{array}$ & $\begin{array}{l}88.94(13.90) \\
75-120\end{array}$ & $\begin{array}{l}98.52(12.77) \\
77-120\end{array}$ & $\begin{array}{l}90.17(14) \\
59-120\end{array}$ & $\begin{array}{l}84.75(18) \\
66-103\end{array}$ \\
\hline Practical & $\begin{array}{l}91.23(17.58) \\
50-120\end{array}$ & $\begin{array}{l}88.29(17.30) \\
50-120\end{array}$ & $\begin{array}{l}94.32(17.68) \\
53-120\end{array}$ & $\begin{array}{l}88.13(15.82) \\
64-120\end{array}$ & $\begin{array}{l}90.10(17.44) \\
64-120\end{array}$ & $\begin{array}{l}88.11(18.13) \\
50-120\end{array}$ & $\begin{array}{l}80.25(20.57) \\
62-100\end{array}$ \\
\hline $\begin{array}{l}\text { Number }(\%) \\
\text { below } \\
\text { average }\end{array}$ & $60(52.63)$ & $35(59.3)$ & $25(45.5)$ & $11(68.8)$ & $12(57.1)$ & $10(55.6)$ & $2(50)$ \\
\hline
\end{tabular}

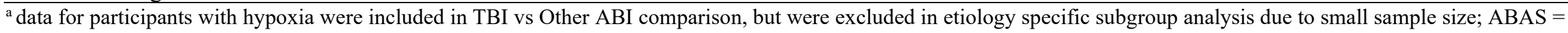
Adaptive Behavior System - Third Edition (ABAS-3); BYI = Beck Youth Inventories - Second Edition (BYI-II); GAC = Global Adaptive Composite. 
Table 3.

Correlations between Children's Demographic and Injury Characteristics, Adaptive Behavior (ABAS) and Mental Health (BYI) ( $n=122)$

\begin{tabular}{|c|c|c|c|}
\hline & BDI-Y & BAI-Y & BSCI-Y \\
\hline Parental Education & .04 & .04 & -.08 \\
\hline Time Since Onset & .04 & .04 & -.08 \\
\hline Household Income ${ }^{a}$ & -.02 & -.11 & .13 \\
\hline GCS (TBI only) & -.09 & -.01 & .15 \\
\hline PTA (TBI Only) & -.02 & -.19 & .14 \\
\hline ABAS GAC & -.10 & $-.22 *$ & .14 \\
\hline Conceptual & -.11 & $-.22 *$ & .18 \\
\hline Social & -.09 & -.14 & $.20 *$ \\
\hline Practical & -.09 & $-.22 *$ & .09 \\
\hline
\end{tabular}


Table 4.

Regression Coefficients for Moderation Models of Children's Functional Status (ABAS GAC) and Age of Onset on Self-Reported Depressive and Anxiety Symptoms, and Self-Concept

\begin{tabular}{|c|c|c|c|c|c|}
\hline Interaction & $R^{2} / \Delta R^{2}$ & $F$ & $B$ & SE & $95 \% \mathrm{CI}$ \\
\hline \multicolumn{6}{|l|}{ BDI-Y } \\
\hline Step 1 & .04 & 1.52 & & & \\
\hline Age at onset & & & .032 & .012 & {$[-.007, .072]$} \\
\hline ABAS GAC & & & -.078 & .138 & {$[-.246, .014]$} \\
\hline \multicolumn{6}{|l|}{ Step 2} \\
\hline ABAS GAC $x$ Age of onset & .001 & 0.12 & .001 & .001 & {$[-.003, .002]$} \\
\hline \multicolumn{6}{|l|}{ BAI-Y } \\
\hline Step 1 & .09 & $3.64 *$ & & & \\
\hline Age at onset & & & .038 & .020 & {$[-.001, .077]$} \\
\hline ABAS GAC & & & $-.134^{* *}$ & .136 & {$[-.326,-.069]$} \\
\hline \multicolumn{6}{|l|}{ Step 2} \\
\hline ABAS GAC $x$ Age of onset & .003 & 0.34 & -.001 & .001 & {$[-.003, .002]$} \\
\hline
\end{tabular}

\section{BSCI-Y}

Step 1 
Age at onset

ABAS GAC

Step 2

ABAS GAC $x$ Age of onset

.012

1.33

$-.004$

.018

$[-.039, .032]$

.078

.059

$[-.039, .194]$

$* p<.05 ; * * p<.01$; ABAS GAC $=$ Adaptive Behavior System - Third Edition, Global Adaptive Composite. BDI-Y = Beck Depression Inventory for Youth; BAI-Y = Beck Anxiety Inventory for Youth; BSCI-Y = Beck Self-concept Inventory for Youth. 
Table 5.

Correlations between Child-Reported Mental Health and Parent-Reported Emotional and Behavioral Functioning in the TBI sample ( $n=55$ )

\begin{tabular}{|c|c|c|c|c|}
\hline \multirow{2}{*}{$\begin{array}{l}\text { Parent report } \\
\text { CBCL Subscales }\end{array}$} & \multirow[b]{2}{*}{$\begin{array}{l}\mathrm{CBCL} \\
M(S D), \text { range }\end{array}$} & \multicolumn{3}{|c|}{ Children's self-reports } \\
\hline & & BDI-Y & BAI-Y & BSCI-Y \\
\hline Total & $58.89(11.15), 31-81$ & $.35^{* *}$ & $.37 * *$ & $-.33^{*}$ \\
\hline Internalizing & $98.89(13), 34-90$ & $.43^{* *}$ & $.44 * *$ & $-.33^{*}$ \\
\hline Anxious/Depressed & 59.09 (9.99), 50-86 & $.35^{* *}$ & $.35 * *$ & -.24 \\
\hline Withdrawn/Depressed & 58.44 (8.40), $50-90$ & $.47^{* *}$ & $.42 * *$ & $-.27 *$ \\
\hline Somatic Complaints & $63.38(10.27), 50-88$ & $.35^{* *}$ & $.33^{*}$ & $-.27^{*}$ \\
\hline Social Problems & $59.75(8.70), 50-78$ & $.31 *$ & $.31^{*}$ & $-.35^{* *}$ \\
\hline Thought Problems & 60.55 (9.42), 50-80 & $.29 *$ & $.32 *$ & $-.27^{*}$ \\
\hline Attention Problems & $61.84(10.44), 50-88$ & $.37 * *$ & .25 & $-.27 *$ \\
\hline Externalizing & $55.72(9.90), 34-81$ & .27 & .22 & $-.35 * *$ \\
\hline Rule-Breaking Behavior & $56.09(6.70), 50-76$ & .21 & .18 & $-.27 *$ \\
\hline Aggressive Behavior & $58.02(7.91), 50-93$ & .26 & .20 & $-.33^{*}$ \\
\hline
\end{tabular}

$* p<.05,{ }^{* *} p<.01$, (2-tailed). CBCL = Child Behavior Checklist; BDI-Y = Beck Depression Inventory for Youth; BAI-Y = Beck Anxiety Inventory for Youth; BSCI-Y = Beck Self-concept Inventory for Youth 
